\title{
Animal language studies: What happened?
}

\author{
Irene M. Pepperberg ${ }^{1}$
}

Published online: 1 July 2016

(C) Psychonomic Society, Inc. 2016

\begin{abstract}
The extent to which nonhuman animals can learn actual human language is a controversial question, but many nonhuman species have acquired elements of a two-way communication system that is, and was, sophisticated enough to enable its use in evaluating cognitive capacities. This article is a personal view of the history of these animal language studies.
\end{abstract}

Keywords Animal cognition · Interspecies communication · Animal language studies $\cdot$ Language evolution

What follows is an opinion piece, from someone who was present and part of the field almost from its inception, who attended the relevant conferences, who experienced firsthand the interactions between the major players and the interactions among these players, the press, and the scientific community at large. As such, it is a personal view of what happened; it is not meant to be a thorough scientific review of all the experiments, criticisms, and rebuttals, or even a thorough review of where we are today. I accept and acknowledge that others will have their own memories, their own interpretations, and their own views.

The 1960s through the mid 1970s was an incredibly exciting time to be involved in studies on animal abilities. For the first time, the Nobel Prize in Physiology or Medicine (1973) had been won by three ethologists — von Frisch, Lorenz, and

Preparation of this article was supported by donors to The Alex Foundation.

Irene M. Pepperberg

impepper@wjh.harvard.edu; impepper@media.mit.edu

1 Department of Psychology, William James Hall, Harvard University, 33 Kirkland Street, Cambridge, MA 02138, USA
Tinbergen. The field of psychology had been shaken up by the aptly named "cognitive revolution"- - the radical notion that levels and types of intelligence in nonhumans formed a continuum with those of humans (e.g., Hulse, Fowler, \& Honig, 1968). These events inspired researchers to study a wide range of behavior - including communication - in various species. Griffin (1976) encouraged his colleagues by arguing that interspecies communication would be a possible window on the minds of animals. Moreover, what came to be known as "animal language studies" were also in progress. Previous attempts to teach language to apes (e.g., Hayes \& Nissen, 1956/1971; Kellogg, 1968) and dolphins (Lilly, 1967), using human speech, had failed. However, researchers had hypothesized that alternative modes of communication might prove fruitful, and were achieving some success. Different labs were using different techniques to establish two-way communication with our nearest relatives - chimpanzees (R. A. Gardner \& Gardner, 1969; Premack, 1971; Rumbaugh et al., 1973), an orangutan (Miles, 1978), and a gorilla (Patterson, 1978). Other labs were investigating similar abilities in nonhuman species not at all closely related to humans (e.g., Herman's (1980) work on dolphins). And the amazing studies on vocal learning in songbirds, showing the striking comparisons between the process of song acquisition and human language learning (e.g., Marler, 1973), inspired me to begin work on training a Grey parrot to use referential speech (Pepperberg, 1981).

Results from the different laboratories were divergent, but complementary. Use of American Sign Language and Signed English (Gardners, Miles, Patterson) allowed for flexibility, innovation, and direct comparisons of communicative acquisition between child and ape. Use of plastic chips to represent labels, taught via a no-fault choice procedure (Premack), provided less information about communication skills but began to elucidate how acquisition of symbolic representation could 
affect cognitive processing. Use of a glorified Skinner box, initially with an ape named Lana (Rumbaugh), removed most of the effects of social interaction to get at which basic concepts could be acquired via associative learning and how such learning could still allow for innovation. Herman's early work ran afoul of animal rights activists, but with new subjects he had begun to show that dolphins could respond to specific cues with specific actions that demonstrated referential comprehension. My parrot started to use the sounds of English speech to identify objects, colors, and shapes. A media storm ensued (e.g., NOVA and BBC Horizon did documentaries; numerous articles were published in places like The New York Times). Not only had we achieved a kind of "Dr. Doolittle" moment, but we felt we could be gaining insights into how language and complex cognition might have evolved in our ancestors. If creatures separated by 300 million years of evolution and with remarkably different-looking brains could all acquire some level of symbolic representation and regular ordering of those symbols, wouldn't that imply something basic in evolution? How might our ancestors have built upon such abilities?

These studies were even more exciting because they began only a decade or so after major competing theories had been proposed for how children acquired language - Chomsky's (1959) innate Language Acquisition Device (LAD) and Skinner's (1957) tabula rasa in which conditioning played a major role. Child developmental laboratories sprung up, gathering data to try to support one side or the other (amazingly, little research had actually previously been done), but the implications of the studies on nonhumans were clear: To state the case in the simplest terms possible, if Chomsky was correct, no nonhuman could possibly acquire anything like language; if Skinner was correct, it was only a matter of time, energy, effort, and the correct procedure that would ensure success.

The stakes were high, and many researchers wrote scholarly articles questioning what exactly nonhumans had learned, disputing the extent of the claims being made (e.g., Bronowski \& Bellugi, 1970; Lachman \& Mister-Lachman, 1974; Lenneberg, cited in Nottebohm, 1973). These articles, and their rebuttals, started serious discussions of truly important questions: for example, what were the actual hallmarks of language; what might the apes', dolphins', and parrot's abilities tell us about language evolution and cognitive processing; what stages did children go through en route to full language; how did codes such as ASL differ from spoken language, and were these differences important? (Note that at one point some scientists questioned if ASL was even a real human language; a full analysis hadn't been published until Stokoe, 1978.) If nothing else, data from these studies spurred research on child language acquisition and cognitive development. As more was learned, the bar kept being raised for the nonhumans: Once nonhumans could use symbols to refer to objects, they needed to use symbols for verbs, then needed to construct phrases, and also needed to use this acquired code to demonstrate complex cognitive processes (categorization, relational concepts, same-different, etc.). In frustration, Fouts (1974) basically argued that language seemed to be defined as whatever it was that apes didn't have. Nevertheless, what our animals did learn provided important insights. Whether or not Premack's plastic chip system could be called "language," only apes who had undergone such training seemingly could learn concepts such as formal analogies (Premack, 1976). Did such training actually alter the apes' brains? Could these data provide information on how symbolic representation, cognitive processing, and brain development might have interacted to make changes in our ancestors en route to modern humans?

At this point, however, no one had argued that problems existed with the data being collected. At least not until Terrace (Terrace, 1979a; Terrace et al., 1979). Terrace reported that his ape, Nim (named Nim Chimpsky, in a stab at Chomsky), learned very little after being trained in sign language but via the techniques of operant conditioning (Fouts, 1983). Other signing apes had been taught in ways based on those used with young children: rich in social interaction, modeling, and referential rewards (if an ape signed something about X, it usually received X or got to do X; e.g., R. A. Gardner \& Gardner, 1969). Terrace and colleagues (1979) argued that because his ape could not create a sentence comparable to one used by adult, oral humans, no ape could acquire anything vaguely resembling human language. Although Terrace (1979a) did raise points about methodology and data interpretation that needed addressing (e.g., the sometimes small numbers of options from which subjects could choose the correct answer and often the small numbers of trials involved, both lowering the statistical power), he did not limit his criticisms to those points. Specifically, he compared ASL-learning chimps not with ASL-learning human infants, but (improperly) with infants acquiring spoken English. Thus, he correctly noted that ASL strings such as YOU ME EAT? lacked the complexity of English syntax, but failed to acknowledge that such strings were one way in which human oral sentences such as "Wanna grab lunch?" might be expressed in sign, particularly by children, and thus were, at many levels, equivalent (note B. T. Gardner \& Gardner, 1998; Van Cantfort \& Rimpau, 1982). He didn't accept that in a system in which one can't increase volume, emphasis occurs by perseveration (Finton \& Smith, 2003; B. T. Gardner \& Gardner, 1998; Hoffmeister, Moores, \& Ellenberger, 1975). He acknowledged that his ape never progressed beyond simple associations between objects, a few actions, and symbols, but not that such associations are often the very first stages in human label acquisition (e.g., Bloom, 1973). (Numerous reasons likely existed for Nim's failures, some of which might have been the huge number, $\sim 40$, of different trainers, few of whom were proficient in sign; or the use of nonreferential food rewards for the acquisition of nonfood signs, thus making the association between sign and object less relevant; see Terrace, 1979b). He did not accept 
evidence presented by other laboratories for spontaneous generation of signs ("cry hurt food" for radishes; Fouts, 1974), or concatenation of computer lexigrams ("coke that is orange" for Fanta; Rumbaugh, 1977). Terrace went even further in his 1979 articles, however, arguing that the other signing studies were no better than his, that their data were not being analyzed appropriately, and that such studies were essentially worthless.

What could have been a series of academic arguments (see, e.g., the exchanges between Schusterman and Herman in the late 1980 s, cited below), even resulting in collaborative efforts (e.g., combining the strengths and eliminating the weaknesses of the varying training and testing techniques to determine something about language primitives and nonhuman cognitive processing), instead devolved into total chaos when the New York Academy of Sciences, in 1980, hosted a conference put together by Thomas Sebeok, a noted researcher in zoosemotics, and Robert Rosenthal, who studied nonverbal communication and how expectancies influenced conclusions (Sebeok \& Rosenthal, 1981). The conference not only had scientists as speakers but also nonscientists like the "Amazing Randi," a professional magician, who demonstrated how easily people could be fooled into seeing what they wanted or expected to see. Sign language researchers were accused of cuing their apes by ostensive signals (even though apes, as it turns out, may have some difficulty interpreting such forms of human action; see Bräuer, Kaminski, Riedel, Call, \& Tomasello, 2006), and of consistently overinterpreting the animals' signs (a possibility in some instances, but not in others; see R. A. Gardner \& Gardner, 1984 , for controlled vocabulary tests). Scientists such as the Rumbaughs vehemently objected to the assault, but at the time argued that only their own computer-based system prevented the problems the conference was addressing, thus showing little affiliation with, or giving any support to, researchers using other techniques (Marx, 1980; Wade, 1980). They thus added to the furor sparked by Sebeok and Rosenthal, who all but called researchers in the field liars, cheats, and frauds (and actually did so in a postconference press gathering; Wade, 1980). The conference was covered by the media (see review for Science; Wade, 1980), and the public brouhaha meant that government agencies - responsive to the blow-back-fairly quickly cut off the funding for all of the studies.

Almost all of the laboratories abandoned their studies of language per se, but the silver lining was that most shifted to using what we called "two-way communication systems" to examine various forms of cognitive processing that relied on symbolic representation - for example, studies on numerical concepts (e.g., Boysen, 1993; Boysen et al., 1993; Matsuzawa, 2009; Pepperberg, 2006; Pepperberg \& Carey, 2012); rule-governed behavior, perception, and cognition (e.g., Herman, 1987, 1988, 2010; Herman et al., 1993; Schusterman \& Gisiner, 1988, 1989; Schusterman \& Krieger, 1984); relational concepts (Pepperberg \& Brezinsky, 1991; Schusterman \& Krieger, 1986); and symbolic equivalence (e.g., Kastak \& Schusterman, 2002;
Pepperberg \& Gordon, 2005; Reiss \& McCowan, 1993). Other researchers examined different forms of rule-governed behavior (and often social learning) that were the basis for syntax, such as the ordered sets of actions needed to solve puzzle boxes and how those ordered sets may be acquired (keas: Miyata, Gajdon, Huber, \& Fujita, 2011; apes: Whiten, 1998; note Terrace, Son, \& Brannon, 2003, on other forms of serial learning in monkeys).

The Rumbaughs, at least for awhile, continued to examine aspects of symbolic communication, although primarily in terms of comparative cognition, studying similarities and differences between bonobos and common chimpanzees with respect to aspects of symbolic labeling and comprehension of sentence frames (reviewed in Savage-Rumbaugh, Brakke, \& Hutchins, 1992). Interestingly, this later work often specifically tested effects of social interaction, acknowledging a significant change in methodology and interpretation. Other researchers examined receptive capacities of dogs, possibly to see if the process of domestication had an effect on referential learning (e.g., Kaminski, Call, \& Fischer, 2004; note Griebel \& Oller, 2012) and still others worked to "crack the code" of communication in nature (e.g., monkeys: Schlenker, Chemla, Arnold, \& Zuberbühler, 2016; song sparrows: Beecher \& Akçay, 2014; toothed whales: Janik, Sayigh, \& Wells, 2006; McCowan \& Reiss, 2001). Some researchers have looked for rule-governed behavior with respect to communication systems by studying nonhumans' (particularly songbirds') understanding of artificial grammars (Beckers, Bolhuis, Okanoya, \& Bewick, 2012; Gentner, Fenn, Margoliash, \& Nussbaum, 2006; Fitch \& Friederici 2012; ten Cate \& Okanoya, 2012).

Thus, although interspecies communication studies may not have taught nonhumans to use "language," nonhumans (and those who studied them) had learned quite a bit. Clearly, some common neural architecture enabled disparate nonhuman species to achieve a level of symbolic representation and rulegoverned behavior, suggesting that some such abilities were likely in their natural communication systems and had evolved for that purpose - it was unlikely that researchers instilled such behavior entirely de novo. Nevertheless, grants for such studies became more and more difficult to obtain, subjects began to die off, and the next generation of students seemed more intrigued by human neurobiology and fMRIs. And, in a somewhat unnerving turn of events, animal rights leaders began using the data obtained by researchers in the animal language/ animal cognition field to push for rules and regulations prohibiting apes and marine mammals from being available for such studies in the future.

As a consequence, we are missing many opportunities. The possibilities of studying nonhumans as models for our ancestral abilities or for how convergent evolution might have led to similar language-like abilities in birds, humans, and marine mammals has significantly decreased - as is the possibility of beginning studies with other vocal learners such as elephants 
(note Stoeger et al., 2012). Fortunately, the field of animal cognition still has pockets of strength, and questions abound: What are the differences in imitative ability (in all its complexitye.g., mimicry vs. emulation vs. imitation) that might be important for human-nonhuman communication systems and acquisition of cognitive concepts (e.g., Nielsen, Subiaul, Galef, Zentall, \& Whiten, 2012)? Given that we know more now about signed languages, their parallels to spoken languages, and how they can evolve over time (e.g., Goldin-Meadow et al., 2015), and more about language pedagogy (e.g., Golinkoff, Can, Soderstrom, \& Hirsh-Pasek, 2015), how much might apes learn if trained appropriately? Given the research on using computer-based communication training and portable systems for children on the autistic spectrum (Ramdoss et al., 2011), where might such training have led with apes and marine mammals? Given that we know more about human languages and are continuing to learn more (e.g., Levinson \& Gray, 2012), are the criteria we once used for nonhuman acquisition fair? With data on those fronts, not to mention knowledge of brain structures and connectivity, and the striking parallels between primate and nonprimate and even nonmammalian communication systems, what might we be able to deduce about the precursors to modern human languages? Might studies of avian vocal learning — with respect to possible avian "missing links," such as bellbirds (flycatchers technically classified as suboscines - nonvocal learners - that nevertheless do learn simple songs; Kroodsma et al., 2013) — tell us, through investigations of convergent evolution, something about what types of brains our ancestors might have been developing? The list can go on, and the implications are clear.

\section{References}

Beckers, G. J. L., Bolhuis, J. J., Okanoya, K., \& Berwick, R. C. (2012). Birdsong neurolinguistics: Songbird context-free grammar claim is premature. Neuroreport, 3, 139-145.

Beecher, M. D., \& Akçay, Ç. (2014). Friends and enemies: How social dynamics shape communication and song learning in song sparrows. In K. Yasukawa (Ed.), Animal behavior (Vol. 3, pp. 33-61). Santa Barbara, CA: Praeger.

Bloom, L. (1973). One word at a time: The use of single word utterances before syntax. The Netherlands: Mouton: The Hague.

Boysen, S. T. (1993). Counting in chimpanzees: Nonhuman principles and emergent properties of number. In S. T. Boysen \& E. J. Capaldi (Eds.), The development of numerical competence: Animal and human models (pp. 39-59). Hillsdale, NJ: Erlbaum.

Boysen, S. T., Berntson, G. G., Shreyer, T. A., \& Quigley, K. S. (1993). Processing of ordinality and transitivity by chimpanzees (Pan troglodytes). Journal of Comparative Psychology, 107, 208-215.

Bräuer, J., Kaminski, J., Riedel, J., Call, J., \& Tomasello, M. (2006). Making inferences about the location of hidden food: Social dog, causal ape. Journal of Comparative Psychology, 120, 38-47.

Bronowski, J., \& Bellugi, U. (1970). Language, name and concept. Science, 168, 669-673.

Chomsky, N. (1959). Review of Verbal Behaviour, by B. F. Skinner. Language, 35, 26-58.
Finton, L., \& Smith, R. (2003). Interpreter discourse: English to ASL expansion /ASL to English compression. Rochester, NY: National Technical Institute for the Deaf.

Fitch, W. T., \& Friederici, A. D. (2012). Artificial grammar learning meets formal language theory: An overview. Philosophical Transactions of the Royal Society B, 367, 1933-1955.

Fouts, R. S. (1974). Language: Origins, definition, and chimpanzees. Journal of Human Evolution, 3, 475-482.

Fouts, R. S. (1983). Chimpanzee language and elephant tails: A theoretical synthesis. In Language in primates (pp. 63-75). New York, NY: Springer.

Gardner, B. T., \& Gardner, R. A. (1998). Development of phrases in the utterances of children and cross-fostered chimpanzees. Human Evolution, 13, 161-188.

Gardner, R. A., \& Gardner, B. T. (1969). Teaching sign language to a chimpanzee. Science, 187, 644-672.

Gardner, R. A., \& Gardner, B. T. (1984). A vocabulary test for chimpanzees (Pan troglodytes). Journal of Comparative Psychology, 1984, 381-404.

Gentner, T. Q., Fenn, K. M., Margoliash, D., \& Nusbaum, H. C. (2006). Recursive syntactic pattern learning by songbirds. Nature, 440, 1204-1207.

Goldin-Meadow, S., Brentari, D., Coppola, M., Horton, L., \& Senghas, A. (2015). Watching language grow in the manual modality: Nominals, predicates, and handshapes. Cognition, 135, 381-395.

Golinkoff, R. M., Can, D. D., Soderstrom, M., \& Hirsh-Pasek, K. (2015). (Baby)Talk to me: The social context of infant-directed speech and its effects on early language acquisition. Current Directions in Psychological Science, 24, 339-344.

Griebel, U., \& Oller, D. K. (2012). Vocabulary learning in a Yorkshire terrier: Slow mapping of spoken words. PLOS ONE, 7(2), e30182. doi:10.1371/journal.pone.0030182

Griffin, D. R. (1976). The question of animal awareness: Evolutionary continuity of mental experience. New York, NY: Rockefeller University Press.

Hayes, K. J., \& Nissen, C. H. (1971). Higher mental functions of a homeraised chimpanzee. In A. M. Schrier \& F. Stollnitz (Eds.), Behavior of non-human primates (Vol. 4, pp. 57-115). New York, NY: Academic Press (Original work published 1956).

Herman, L. M. (1980). Cognitive characteristics of dolphins. In L. M. Herman (Ed.), Cetacean behavior (pp. 408-409). New York, NY: Wiley.

Herman, L. M. (1987). Receptive competencies of language-trained animals. In J. S. Rosenblatt, C. Beer, M.-C. Busnel, \& P. J. B. Slater (Eds.), Advances in the study of behavior (Vol. 17, pp. 1-60). New York, NY: Academic Press.

Herman, L. M. (1988). The language of animal language research: A reply to Schusterman and Gisiner. The Psychological Record, 38, 349-362.

Herman, L. M. (2010). What laboratory research has told us about dolphin cognition. International Journal of Comparative Psychology, 23, 310-330.

Herman, L. M., Kuczaj, S. A., \& Holder, M. D. (1993). Response to anomalous gestural sequences by a language-trained dolphin: Evidence for processing of semantic relations and syntactic information. Journal of Experimental Psychology: General, 122, 184 194.

Hoffmeister, R. J., Moores, D. F., \& Ellenberger, R. L. (1975). Some procedural guidelines for the study of the acquisition of sign languages. Sign Language Studies, 7, 121-137.

Hulse, S. H., Fowler, H., \& Honig, W. K. (Eds.). (1968). Cognitive processes in animal behavior. Hillsdale, NJ: Erlbaum.

Janik, V. M., Sayigh, L. S., \& Wells, R. S. (2006). Signature whistle shape conveys identity information to bottlenose dolphins. Proceedings of the National Academy of Sciences of the United States of America, 103, 8293-8297. 
Kaminski, J., Call, J., \& Fischer, J. (2004). Word learning in a domestic dog: Evidence for 'fast mapping'. Science, 304, 1682-1683.

Kastak, C. R., \& Scuhsterman, R. J. (2002). Sea lions and equivalence: Expanding classes by exclusion. Journal of the Experimental Analysis of Behavior, 78, 449-465.

Kellogg, W. N. (1968). Communication and language in the home-raised chimpanzee. Science, 162, 423-438.

Kroodsma, D. E., Hamilton, D., Sánchez, J. E., Byers, B. E., FandiñoMariño, H., Stemple, D. M., . . Powell, G. V. N. (2013). Behavioral evidence for song learning in the suboscine bellbirds (Procnias spp.; Cotingidae). Wilson Journal of Ornithology, 125, 1-14.

Lachman, R., \& Mister-Lachman, J. (1974). Language in man, monkeys, and machines. Science, 185, 871-873.

Levinson, S., \& Gray, R. (2012). Tools from evolutionary biology shed new light on the diversification of languages. Trends in Cognitive Sciences, 16, 167-173.

Lilly, J. C. (1967). Dolphin's vocal mimicry as a unique ability and a step toward understanding. In K. Salzinger \& S. Salzinger (Eds.), Research in verbal behavior and some neurophysiological implications (pp. 21-27). New York, NY: Academic Press.

Marler, P. (1973). Speech development and bird song: Are there any parallels? In G. A. Miller (Ed.), Communication, language, and meaning (pp. 73-83). New York, NY: Basic Books.

Marx, J. (1980). Ape-language controversy flares up. Science, 207, 13301333.

Matsuzawa, T. (2009). Symbolic representation of number in chimpanzees. Current Opinions in Neurobiology, 19, 92-98.

McCowan, B., \& Reiss, D. L. (2001). The fallacy of 'signature whistles' in bottlenose dolphins: A comparative perspective of 'signature information' in animal vocalizations. Animal Behaviour, 62, 11511162.

Miles, H. L. (1978). Language acquisition in apes and children. In F. C. C. Peng (Ed.), Sign language and language acquisition in man and ape (pp. 108-120). Boulder, CO: Westview Press.

Miyata, H., Gajdon, G. K., Huber, L., \& Fujita, K. (2011). How do keas (Nestor notabilis) solve artificial-fruit problems with multiple locks? Animal Cognition, 14(1), 45-58.

Nielsen, M., Subiaul, F., Galef, B., Zentall, T. R., \& Whiten, A. (2012). Social learning in humans and nonhuman animals: Theoretical and empirical discussions. Journal of Comparative Psychology, 126, $100-113$.

Nottebohm, F. (1973). A zoologist's view of language phenomena. In E. H. Lenneberg \& E. Lenneberg (Eds.), Foundations of language development: A multidisciplinary approach (pp. 61-121). New York, NY: Academic Press.

Patterson, F. G. (1978). Linguistic capabilities of a lowland gorilla. In F. C. C. Peng (Ed.), Sign language and language acquisition in man and ape (pp. 161-201). Boulder, CO: Westview Press.

Pepperberg, I. M. (1981). Functional vocalizations by an African Grey parrot (Psittacus erithacus). Zeitschrift für Tierpsychologie, 55, 139-160.

Pepperberg, I. M. (2006). Ordinality and inferential abilities of a Grey parrot (Psittacus erithacus). Journal of Comparative Psychology, 120, 205-216.

Pepperberg, I. M., \& Brezinsky, M. V. (1991). Acquisition of a relative class concept by an African Grey parrot (Psittacus erithacus): Discriminations based on relative size. Journal of Comparative Psychology, 105, 286-294.

Pepperberg, I. M., \& Carey, S. (2012). Grey parrot number acquisition: The inference of cardinal value from ordinal position on the numeral list. Cognition, 125, 219-232.

Pepperberg, I. M., \& Gordon, J. D. (2005). Number comprehension by a Grey parrot (Psittacus erithacus), including a zero-like concept. Journal of Comparative Psychology, 119, 197-209.

Premack, D. (1971). On the assessment of language-competence in the chimpanzee. In A. M. Schrier \& F. Stollnitz (Eds.), Behavior of nonhuman primates (Vol. 4, pp. 186-228). New York, NY: Academic Press.

Premack, D. (1976). Intelligence in ape and man. Hillsdale, NJ: Erlbaum.

Ramdoss, S., Lang, R., Mulloy, A., Franco, J., O'Reilly, M., Didden, R., \& Lancioni, G. (2011). Use of computer-based interventions to teach communication skills to children with autism spectrum disorders: A systematic review. Journal of Behavioral Education, 20, 55-76.

Reiss, D. L., \& McCowan, B. (1993). Spontaneous vocal mimicry and production by bottlenose dolphins (Tursiops truncatus): Evidence for vocal learning. Journal of Comparative Psychology, 107, 301312.

Rumbaugh, D. M. (1977). Language learning by a chimpanzee. New York, NY: Academic Press.

Rumbaugh, D. M., von Glasersfeld, E. C., Warner, H., Pisani, P., Gill, T. V., Brown, J. V., \& Bell, C. L. (1973). A computer-controlled language training system for investigating the language skills of young apes. Behavior Research Methodology and Instrumentation, 5, 385392.

Savage-Rumbaugh, E. S., Brakke, K., \& Hutchins, S. (1992). Linguistic development: Contrasts between co-reared Pan troglodytes and Pan paniscus. In T. Nishida, W. C. McGrew, P. Marler, M. Pickford, \& F. B. M. de Waal (Eds.), Topics in primatology: Human origins (pp. 51-66). Tokyo, Japan: University of Tokyo Press.

Schlenker, P., Chemla, E., Arnold, K., \& Zuberbühler, K. (2016). Pyowhack revisited: Two analyses of putty-nosed monkey alarm calls. Lingua, 171, 1-23.

Schusterman, R. J., \& Gisiner, R. C. (1988). Artificial language comprehension in dolphins and sea lions: The essential cognitive skills. The Psychological Record, 38, 311-348.

Schusterman, R. J., \& Gisiner, R. C. (1989). Please parse the sentence: Animal cognition in the Procrustean bed of linguistics. Psychological Record, 39, 1-18.

Schusterman, R. J., \& Krieger, K. (1984). California sea lions are capable of semantic comprehension. The Psychological Record, 34, 3-24.

Schusterman, R. J., \& Krieger, K. (1986). Artificial language comprehension and size transposition by a California sea lion (Zalophus californianus). Journal of Comparative Psychology, 100, 348-355.

Sebeok, T. A., \& Rosenthal, R. (Eds.). (1981). The Clever Hans phenomenon: Communication with horses, whales, apes, and people. New York, NY: New York Academy of Sciences (Annals).

Skinner, B. F. (1957). Verbal behavior. New York, NY: AppletonCentury-Crofts.

Stoeger, A. S., Mietchen, D., Oh, S., de Silva, S., Herbst, C. T., Kwon, S., \& Fitch, W. T. (2012). An Asian elephant imitates human speech. Current Biology, 22, 2144-2148.

Stokoe, W. C. (1978). Sign language structure. Silver Spring, MD: Linstock Press.

ten Cate, C., \& Okanoya, K. (2012). Revisiting the syntactic abilities of non-human animals: Natural vocalizations and artificial grammar learning. Philosophical Transactions of the Royal Society B, 367(1598), 1984-1994.

Terrace, H. S. (1979a). Is problem-solving language? Journal of the Experimental Analysis of Behavior, 31, 151-170.

Terrace, H. S. (1979b) Nim. New York, NY: Knopf.

Terrace, H. S., Petitto, L. A., Sanders, R. J., \& Bever, T. G. (1979). Can an ape create a sentence? Science, 206, 891-902.

Terrace, H. S., Son, L. K., \& Brannon, E. M. (2003). Serial expertise of rhesus macaques. Psychological Science, 14, 66-73.

Van Cantfort, T. E., \& Rimpau, J. B. (1982). Sign languge studies with children and chimpanzees. Sign Language Studies, 34, 15-72.

Wade, N. (1980). Does man alone have language? Apes reply in riddles and a horse says neigh. Science, 208, 1349-1351.

Whiten, A. (1998). Imitation of the sequential structure of actions by chimpanzees (Pan troglodytes). Journal of Comparative Psychology, 112, 270-281. 